\title{
LOBBYING ACTIVITIES OF FIRMS WITH VARIOUS INTERESTS
}

\author{
Yumiko Baba \\ Aoyamagakuin University, Tokyo Japan \\ Email: yumiko.baba@gmail.com
}

\begin{abstract}
We examine lobbying activities of two players theoretically and experimentally by using Tullock contests. Players' interests can be different. In one extreme, two players' interests are independent where the winner takes all. In the other extreme, players' interests are perfectly aligned where the winner and the loser enjoy the prize value equally. Choosing the host cities of the FIFA World Cup and of the Olympic Game are in the former example and two firms in the oil industry engaging in the lobbying activities against the tough environmental regulation are in the latter example. Our model incorporates all the other intermediate cases. Our model is also interpreted as a model of lobbying activities of two firms cross holding each other's shares. We show theoretically that the equilibrium amounts of investment of players are the same in the simultaneous and in the sequential contests. Based on our theoretical results, we ran experiments to examine whether players' investment decisions were influenced by how aligned their interests were. Players over-invested and variances were large both in the sequential and in the simultaneous games, but they played the Nash equilibrium $76.49 \%$ of the time in the simultaneous game and $75.30 \%$ in the sequential game when their interests were perfectly aligned. Furthermore, our experiment observed that investment decisions between the simultaneous and the sequential contests are similar, except the case where two players' interests were perfectly aligned.
\end{abstract}

Keywords: Tullock Contest, Lobbying \&Experiments.

\section{Introduction}

This paper analyzes lobbying activities of two players whose interests are varied theoretically and experimentally. In one extreme, two players' interests are independent where the winner's payoff is the prize value minus the cost of nonrefundable expenditure while the loser simply incurs the cost of nonrefundable expenditure, that is, the winner takes all. In the other extreme, players' interests are perfectly aligned where the winner and the loser enjoy the prize value equally. All the intermediate cases between independent and perfectly aligned interests are considered. For example, two firms in the oil industry engage in lobbying activities against a strict environmental regulation rule is in the latter example because neither of them wants the rule to be enacted and we can treat their interests are perfectly aligned. Choosing the host cities of the FIFA World Cup and the Olympic Game is an example where players' interests are independent in the sense that the winner enjoys the prize fully while each loser just incurs the cost of nonrefundable expenditure on lobbying activities. We analyze these situations by Tullock contest model and show that the equilibrium investment levels are the same in the simultaneous and in the sequential contests. Our model is also interpreted as lobbying activities of two firms who cross hold their shares each other. 


\section{Research problem}

We theoretically and experimentally analyzed lobbying activities of two players whose interests are varied. We introduced a parameter, $\alpha(0 \leq \alpha \leq 1)$, which captures how aligned two players' interests are into the basic Tullock contest with two players. We characterize the equilibrium of simultaneous and sequential contests and derive the proposition that players invest the same amount in simultaneous and in sequential contests. Based on our theoretical result, we ran laboratory experiments. We set three different values of $\alpha$ and examined whether subjects behaved differently when $\alpha$ changed. We also examined whether subjects invested the same amount between simultaneous and sequential contests.

\section{Review of the relevant literature}

Majority of previous works on contests focused on the situation where all the players determine their expenditures simultaneously. This framework is first introduced by(Tullock, 1980). Recently, several authors examine sequential contests. Firstly, Morgan, (n.d.) analyzed sequential moves by two players. He analyzed the simultaneous and the sequential contests when two ex-ante identical players competed for a prize. Each player drew his/her prize value from publicly known probability distribution function and knew only his/her realized prize value. He showed that the sequential contest where the player with higher value on the prize moved first was Pareto superior to the simultaneous contest and the sequential contest where the player with lower value on the prize moved first. Secondly, Megidish \& Sela, (n.d.)analyzed two period contests with one prize available in each period. They considered both complements and substitutes with and without budget constraints and characterized the equilibrium. Sela, (n.d.) did similar exercise as Megidish \& Sela, (n.d.) did, but they analyzed all-pay auction without budget constraint. Thirdly, Gurtler, (2005) analyzed group contests where groups were allowed to determine their sharing rules. He showed that the smaller group acted prior to the bigger group to determine their sharing rule. This weakened the competition and decreased the total expenditures of all the groups. Finally, there were some experimental works on sequential contests. Irfanoglu, et al., (2010)ran experiments on election contests and found that the winner of the first battle won the overall contests with much higher probability than the loser of the first battle. They also found that the total expenditure was higher in the sequential contest than in the simultaneous contest. Baba, (2014) conducted experiments on Colonel Blotto game and also observed that the total expenditure was higher in the sequential contest than in the simultaneous contest.

Although most previous works considered the case where the winner took all, it is not the case in the above mentioned oil companies' example. There are lots of examples which fit to the assumption of players with aligned interests. Automobile companies lobbying against a tougher fuel economy regulation and the incumbents in telecommunications industry lobbying against entry enhancing rule are among many. Although there are lots of examples which fit to our framework in the practical world, this is the first attempt to consider the effect of the degree of similarity of players' interests on lobbying decisions theoretically and experimentally and we can learn a lot. 


\section{Method}

4-1 offers a theoretical model and 4-2 explains the experimental design based on the theoretical results in 4-1.

\section{4-1. Model}

We interpret our model as two firms who cross hold each other's shares engage in lobbying activities hereafter for simplicity.

Two risk neutral firms compete for a prize in a contest. The value of the prize to firm $i(i=1,2)$ is common and is denoted by $V>0$. A firm invests in irreversible effort outlay, $x_{i}$. We call $x_{i}$ as firm $i$ 's $(i=1,2)$ investment level hereafter. For example, we can interpret investment level is an expenditure on lobbying activity and the prize is a value of legislation. Given the investment level taken by both firms, firm $i(i=1,2)$ wins the prize with probability $p_{i}\left(x_{1}, x_{2}\right)=\frac{x_{i}}{x_{i}+x_{j}}, i=1,2$ and $j \neq i$. So, we use contest introduced by [18] here. The expected payoff of firm $i$ is expressed as follows.

$$
E U\left(x_{i}, x_{j}\right)=\frac{x_{i}}{x_{i}+x_{j}} V-x_{i} \ldots(2-1)
$$

We assume $p_{i}\left(x_{1}, x_{2}\right)=\frac{x_{i}}{x_{i}+x_{j}}$ for simplicity. We assume that firms cross hold their shares each other. Specifically, $\alpha_{i j}(i, j=1,2)$ denotes the firm $i$ 's shares of firm $j \neq i$. For simplicity, we assume $\alpha_{11}+\alpha_{21}=\alpha_{12}+\alpha_{22}=1$.

Assumption 1. $\alpha_{i i}+\alpha_{j i}=1$, for $i=1,2$ and $j \neq i$.

Assumption 2. $\alpha_{i i}-\alpha_{i j} \geq 0$, for $i=1,2$ and $j \neq i$.

Assumption 2 assures the equilibrium investment level is non-negative. Assumptions 1 and 2 together imply that $\alpha_{11}-\alpha_{12}=\alpha_{22}-\alpha_{21}=\alpha_{11}+\alpha_{22}-1,{ }^{\forall} \alpha_{11}, \alpha_{12}, \alpha_{21}, \alpha_{22}$ and it is the driving force to obtain two firm's equilibrium investments are the same across the simultaneous and the sequential game because firm $i$ 's incentive to win measured by the difference of its payoff when it wins and it loses given an investment level is the same as that of firm $j(j \neq i)$. Then, both firms' incentives to win are the same regardless of the values of $\alpha_{i j}$ s.

Assumption 3. $\alpha_{11}-\alpha_{22} \geq 0$

Assumption 3 allows two firms being asymmetric in stock holding structures. Assumption 3 means we denote the firm who owns more of its own shares as firm 1 without loss of generality. The symmetric case is a special case of assumption 3 where $\alpha_{11}-\alpha_{22}=0$. Note that we impose symmetric assumptions on the prize values, the cost functions, the winning probabilities and the stock holding structures are the only source of asymmetry of two firms.

\section{4-1-1. Simultaneous contests}

In the simultaneous contest, two symmetric firms, 1 and 2 simultaneously invest to acquire the prize valued, $V>0$. Firm $i(i=1,2$ and $i \neq j)$ solves the following problem. 


$$
\operatorname{Max}_{x_{i}} \frac{x_{i}}{x_{i}+x_{j}} \alpha_{i i} V+\frac{x_{j}}{x_{i}+x_{j}} \alpha_{i j} V-x_{i}, i=1,2 \text {. }
$$

Solving two F.O.C.s of (2-1) w.r.t. $x_{1}$ and $x_{2}$ by using $\alpha_{11}-\alpha_{12}=\alpha_{11}+\alpha_{22}-1=\alpha_{22}-\alpha_{21}$ yields proposition 1 .

\section{Proposition1.}

The unique Nash equilibrium of the simultaneous contest is $x_{1}{ }^{*}=x_{2}{ }^{*}=\frac{\left(\alpha_{11}+\alpha_{22}-1\right)}{4} V$.

\section{4-1-2. Sequential contests when firm 1 moves first}

This subsection assumes firm 1 invests in period 1 and firm 2 invests in period 2 after observing firm 1's investment and characterizes the subgame perfect Nash equilibrium by using backward induction. Notations are the same as those in in period 2.

$\operatorname{Max}_{x_{2}} \frac{x_{1}}{x_{1}+x_{2}} \alpha_{21} V+\frac{x_{2}}{x_{1}+x_{2}} \alpha_{22} V-x_{2} \ldots$ (2-2)

We can obtain firm 2's best response function by solving F.O.C. of (2-2)for $x_{2}$. $x_{2}\left(x_{1}\right)=\sqrt{\left(\alpha_{22}-\alpha_{21}\right) x_{1} V}-x_{1} \ldots(2-3)$

Given (2-3), firm1 solves the following problem in period 1.

$$
\operatorname{Max}_{x_{1}} \frac{x_{1}}{x_{1}+x_{2}} \alpha_{11} V+\frac{x_{2}}{x_{1}+x_{2}} \alpha_{12} V-x_{1} \ldots(2-4)
$$

Solving F.O.C. of (2-4) for $x_{1}$, simplifying the outcome by using $\alpha_{11}-\alpha_{12}=\alpha_{11}+\alpha_{22}-1$ $=\alpha_{22}-\alpha_{21}$ yields proposition 2 .

Proposition2. The unique subgame Nash equilibrium of the sequential contest when player1 moves in period1 and player2 moves in period2 is $x_{1}^{* *}=x_{2}^{* *}=\frac{\left(\alpha_{11}+\alpha_{22}-1\right)}{4} V$.

\section{4-1-3. Sequential contest when firm 2 moves first}

This subsectionreverses the order of firms' moves analyzed in subsection 4-2. Now, firm 2 decides his investment level, $x_{2}$, in period 1 and firm 1 decides her investment level, $x_{1}$, in period 2 after observing $x_{2}$. The technique to characterize the unique subgame perfect equilibrium is the same as that used in 4-2. Therefore, we omit the details and summarize the result in proposition 3.

\section{Proposition3.}

The unique subgame Nash equilibrium of the sequential contest when player 2 moves in period 1 and player 1 moves in period 1 is $x_{1}^{* * *}=x_{2}^{* * * *}=\frac{\left(\alpha_{11}+\alpha_{22}-1\right)}{4} V$.

\section{4-1-4. Comparison of the simultaneous and the sequential contests}

From proposition 1,2, and 3, we can obtain proposition 4.

\section{Proposition4.}


The equilibrium total investment level in the simultaneous contest, that in the sequential contests when firm 1 moves in period 1 and firm 2 moves in period 2, that in the sequential contest when firm 2 moves in period 1 and firm 1 moves in period 2.

\section{Proof.}

Obvious from propositions 1, 2, and 3 .

\section{4-2. Experimental Design}

Based on the theoretical results obtained in subsection 4-1, we ran laboratory experiments. The experiments were conducted in Aoyamagakuin University in Tokyo, Japan in December 2014. We recruited the subjects from the Department of Economics and Department of Business. This recruitment process considered the point made by Binmore and Shaked (2010), which advised us that decreasing uncertainty was important for a successful experimental design. Most experimental works on contests including (Chowdhury, et al., 2014; Sheremeta, n.d.; Sheremeta, n.d.) artificial experimental money and applied pre announced exchange rates between artificial experimental money and cash to pay for the subjects after experiments. Baba, (n.d.) found artificial experimental money could cause framing effect and the behaviors of the subjects were affected by the exchange rate even though everything was the same in terms of cash. Therefore, we decided not to use experimental money in our experiments and to use cash. There were 56 subjects in total and they were divided randomly into 4 groups. $2 \times 3$ design was adapted where the first variable was the order of the players (simultaneous or sequential) and the second variable was $\alpha_{i j}$, where $i=1,2$ and $j=1,2$. We used three sets of $\alpha_{i j} \mathrm{~s}$ ( $i=$ 1,2 and $j \neq i$ ). The first one was $\alpha_{11}=\alpha_{22}=1, \alpha_{12}=\alpha_{21}=0$ (denoted by $\alpha=1$ hereafter), the second one was $\alpha_{11}=\alpha_{22}=0.75, \alpha_{12}=\alpha_{21}=0.25$ (denoted by $\alpha=0.75$ hereafter) and the third one was $\alpha_{11}=\alpha_{12}=\alpha_{22}=\alpha_{22}=0.5$ (denoted by $\alpha=0.5$ hereafter). Each session consisted of 12 rounds after 1 round of trial. At the beginning of each round of each session, each subject in each group was randomly matched with another subject in the same group, was given initial endowment of 800 Japanese yen (approximately $\$ 6.78$ because $\$ 1$ is equal to 118 Japanese yen on average in December 2014) and played the Tullock contest with the prize value, $V$, being 800 Japanese yen (approximately \$6.78). The university rule required us not to make any subject ending up with a negative payoff. So, we set the initial endowment being equal to the prize value. 2 out of 14 subjects and 2 out of 12 sessions were randomly chosen and the chosen subjects were actually paid in Japanese yen after the whole experiment was over. Following the literature, we assumed that desire to win and risk attitude were also important factors to determine the amount of investment and measured them. Risk attitude was measured by the same procedure as(Holt \& Laury, n.d.). More precisely, we offered two options to each subject. Option A offered a subject 100 Japanese yen (approximately \$0.85) for sure and option B offered 300 Japanese yen (approximately \$2.54) with some nonnegative probability, but paid nothing otherwise. So, option A was the safe option and option B had some risk. We increased the probability of the 300 Japanese yen payment of option B from o to 1 and observed when subjects switched from option A to option B. A more risk averse subject was supposed to shift to option B when the probability of 300 Japanese yen payment became high enough while a more less risk averse subject was supposed to switch to option B earlier. Following Price \& Sheremeta, (n.d.), desire to win was measured by replacing the value of the prize to be 0 Japanese yen. Table 1 summarized our experimental design. The subjects in each group played 4 sessions. For example, those in group 1 (G1) played the simultaneous contest with $\alpha=1$ 
(SIM1) first. Next, they played the sequential contest with $\alpha=1$ (SEQ1). Thirdly, they played the simultaneous contest with $\alpha=0.75$ (SIMo.75). Lastly, they played the sequential contest with $\alpha=0.75$ (SEQ0.75).

\section{Table 1: Summary of experimental design}

\begin{tabular}{|l|l|l|l|l|}
\hline & Session 1 & Session 2 & Session 3 & Session 4 \\
\hline G1 & SIM 1 & SEQ1 & SIM 0.75 & SEQ0.75 \\
\hline G2 & SEQ0.75 & SIM 0.75 & SEQ1 & SIM 1 \\
\hline G3 & SIM 1 & SEQ1 & SIMo.5 & SEQ0.5 \\
\hline G4 & SEQ0.5 & SIMo.5 & SEQ1 & SIM 1 \\
\hline
\end{tabular}

\section{Data analysis}

\section{5-1. Summary of the experimental data}

Table 2 summarizes the averages and the variances of sessions described in Table 1 and compared them with the averages and the variance of the Nash equilibrium. We could see that over investment was observed and the variances are large, which was the same as most previous works such as Sheremeta, (n.d.) observed.

\section{Table 2: Summary of the Experimental Data}

\begin{tabular}{|l|l|l|l|l|}
\multicolumn{2}{c}{ Average investment } & Vash equilibrium & Data & $\begin{array}{l}\text { Nash } \\
\text { equilibrium }\end{array}$ \\
& Data & & & O \\
\hline G12SIM1 & 351 & 200 & 72273 & O \\
\hline G12SEQ1 & 345 & 200 & 86529 & O \\
\hline G34SIM1 & 392 & 200 & 53019 & O \\
\hline G34SEQ1 & 302 & 200 & 59998 & O \\
\hline G12SIM0.75 & 166 & 100 & 33248 & O \\
\hline G12SEQ0.75 & 116 & 100 & 37405 & O \\
\hline G34SIM0.5 & 24 & 0 & 11949 & O \\
\hline G34SEQ0.5 & 127 & 0 & 55809 & \\
\hline
\end{tabular}

Note: We use the similar notations as in Table $1 . G_{i j}(i j=12$, or 34$)$ implies that subjects in group $\mathrm{i}$ and $\mathrm{j}$ played the corresponding contest.

Almost no one invested the exact Nash equilibrium amount except G34AIMo.5 and G34SEQ0.5; subjects invested the Nash equilibrium amount of $\mathrm{o}$ at $58.9 \%$ (99 out of 168 times) of the time in G34SIM0.5 and at 50.6\% (85 out of 168 times) in G34SEQ0.5.

Next, Figure 1 and 2 show the histograms of the experimental data, where we use the same notations as in Table 1 and 2 to save the space. The horizontal axes of Figure 1 and 2 are the investment level measured by Japanese yen and each bar $k(k=0,100,200, \ldots, 800)$ implies the number of the rounds $[k, k+90]$ for $k=0,1,2, \ldots, 700$ and 800 for $k=800$. The vertical axis measured the percentages of each range of investment was observed. 


\section{Asia Pacific Journal of Advanced Business and Social Studies}

ISBN (eBook): 9780994365675 | ISSN : 2205-6033

Year: 2017 , Volume: 3, Issue: 2

A P I A R

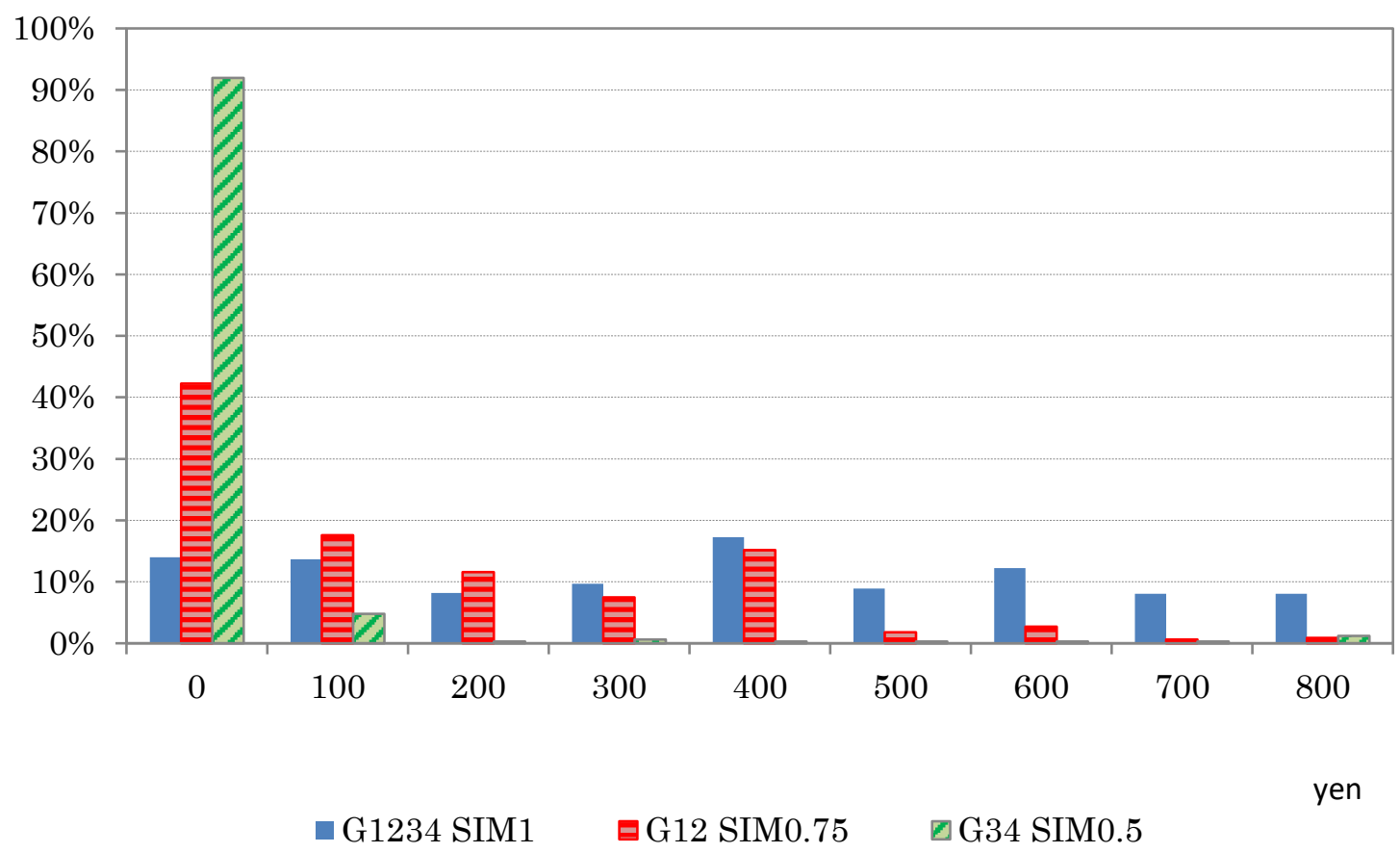

Figure 1: Investment in Three Simultaneous Games

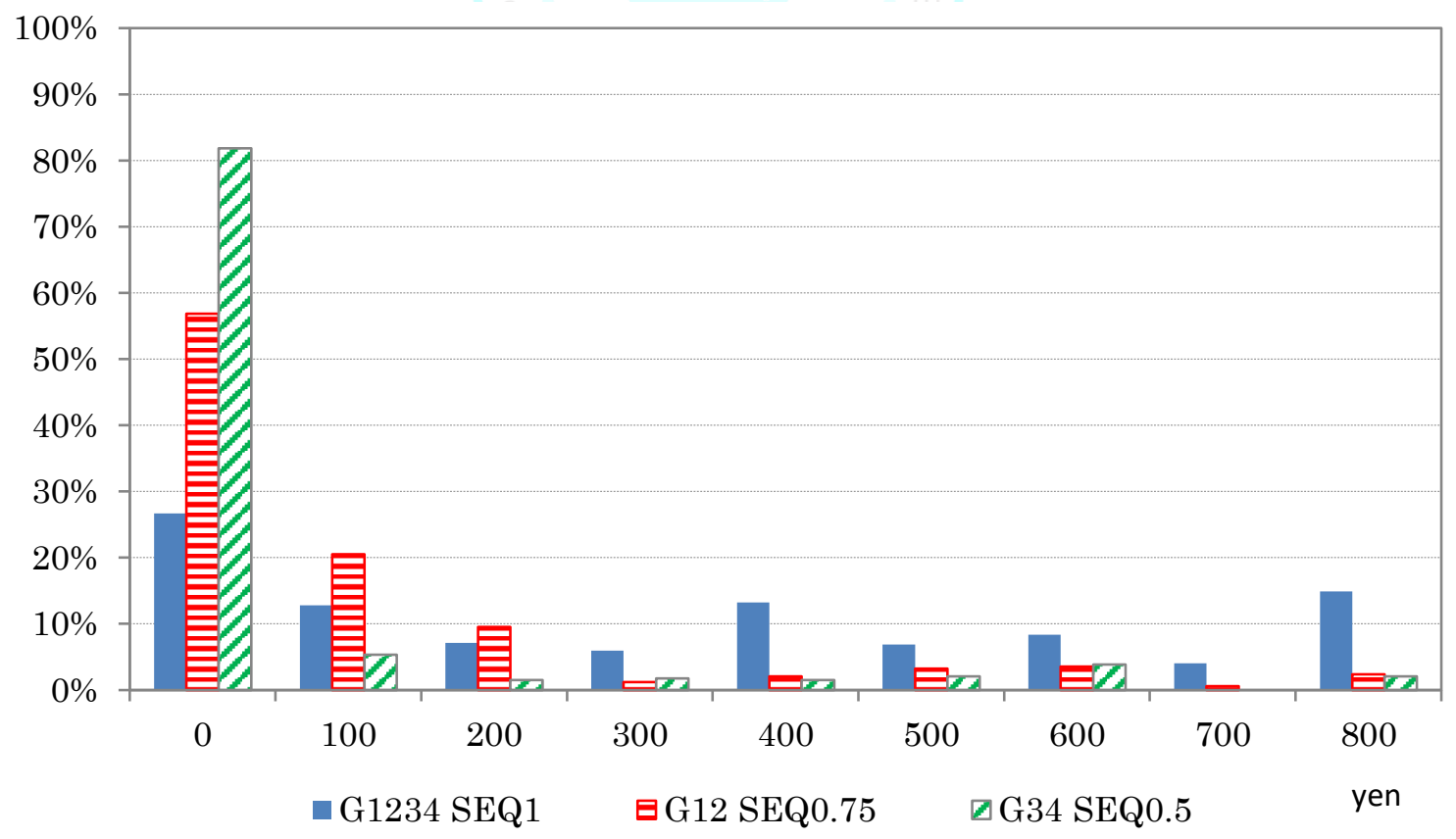

Figure2: Investment in Three Sequential Games

Asia Pacific Institute of Advanced Research (APIAR) 


\section{5-1. Regression outcomes}

This subsection reports the outcomes of various regressions. Throughout this section, we used eViews and ran regressions by using random effect model with panel data. We used investment as dependent variable and constant (denoted by C), risk attitude (denoted by RISK), winning or losing in the previous round (denoted by WL), willingness to win (denoted by PRIZEo), and rounds (denoted by ROUND). ${ }^{* *}$ is $1 \%$ statistically significant, ${ }^{* *}$ is $5 \%$ statistically significant, and ${ }^{*}$ is $10 \%$ statistically significant.

Table 3: Regression outcomes of simultaneous contests and sequential contests.

\begin{tabular}{|l|l|l|l|l|l|}
\hline & C & RISK & WL & PRIZEO & ROUND \\
\hline G1234SIM1 & $397.6683^{* * *}$ & $-10.4061^{*}$ & $47.9634^{* * *}$ & $0.5936^{* * *}$ & $-3.9510^{* *}$ \\
\hline G1234SEQ1 & $311.9659^{* * *}$ & 1.3547 & 13.5518 & 0.0231 & -0.7943 \\
\hline G12SIM0.75 & $166.8987^{* * *}$ & -2.6756 & $62.7326^{* * *}$ & $0.1567^{* * *}$ & $-8.186^{* * *}$ \\
\hline G12SEQ0.75 & $231.7435^{* * *}$ & -7.8773 & $54.7135^{* * *}$ & $-0.0692^{*}$ & $-7.4224^{* * *}$ \\
\hline G34SIM0.5 & 4.2124 & 2.6610 & 13.4803 & 0.0615 & -1.9815 \\
\hline G34SEQ0.5 & 110.8232 & -2.0084 & $30.7887^{* *}$ & 128.5674 & $-7.2878^{* * *}$ \\
\hline
\end{tabular}

Table 3 told us that WL influenced investment decisions except G1234SEQ1 and G34SIMo.5 while RISK did not play a big role in investment decisions. The learning effect was observed except G34SIM0.5 where $78.57 \%$ subjects chose the Nash equilibrium investment level of o from the first round and there was little room for learning.

\section{5-2. The effects of alignment in interests on investment decisions}

This subsection compares pairs of different sessions and groups analyzed in subsection 5-1 to examine whether subjects behaved differently in three different parameter sets of $\alpha \mathrm{s}$, that is, $\alpha=1,0.75$, and 0.5. We have six pairs to examine; (1) G12SIM1 and G12SIMo.75, (2) G12SEQ1 and G12SEQ0.75, (3) G34SIM1 and G34SIMo.5, (4) G34SEQ1 and G34SEQ0.5, (5) G12SIMo.75 and G34SIMo.5, and G12SEQ0.75 and G34SEQ0.5. To examine (5) and (6), we tested the hypothesis that we cannot reject that investment behaviors of G12SIM1 (resp. G12SEQ1) and G34SIM1(resp. G34Q1) were the same. We introduced dummy variable (DUMMY) which took 1 in G12SIM1 (resp. G12SEQ1) and o in G34SIM1 (resp. G34SEQ1). Our regression outcome told us that the probability of the coefficient of DUMMY equal to 0 is 0.27 in G12SIM1 and G34SIM1 and it is 0.71 in G12SEQ1 and G34SEQ1 which means that we cannot reject the hypothesis that subjects' behaviors in G12SIM1 (resp. G12SEQ1) and G34SIM1 (resp. G34Q1) were statistically the same. This allowed us to run regressions to examine the effects of alignment in interests on investment decisions. We introduced a dummy variable (DUMMY) which took 1 in the smaller value of $\alpha$ and o in the smaller value of $\alpha$ in each of (1), (2), (3), (4), (5), and (6). Our regression outcomes told us that the probability of the coefficient of DUMMY equal to o was 0.00 for all 6 pairs of (1), (2), (3), (4), (5), and (6) above, which means that subjects behaved differently when $\alpha$ (which captured how alignment subjects' interests were) changed.

\section{5-3. Comparisons of simultaneous and sequential contests}

This subsection compares subjects' investment behaviors in simultaneous and sequential contests given a parameter, $\alpha$. We used the same technique we used in 5-4. We have 5 pairs; (1) G12SIM1 and G12SEQ1. (2) G34SIM1 and G34SEQ1, (3) G1234SIM1 andG1234SEQ1, (4) G12SIM0.75 and G12SEQ0.75, (5) G34SIMo.5 and G34SEQ0.5. We introduced a dummy 
variable (DUMMY) which took 1 in SIM and o in SEQ in each of (1), (2), (3), (4), and (5). Our regression outcomes told us that the probability of the coefficient of DUMMY equals to 0 was 0.82 in (1), 0.20 in (2), 0.31 in (3), 0.54 in (4), and 0.08 in (5), which means that we cannot reject that subjects' behaviors were the same between simultaneous and sequential contestsexcept when their interests were perfectly aligned. When $\alpha=0.5$, Table 3 shows that there was learning effect in G34SEQ0.5 while learning effect was not observed in G34SIMo.5. Since the second movers could observe the first mover's investment level, they were confirmed that playing o was the equilibrium after observing o investment by the first movers and it facilitated learning.

\section{Conclusions}

We analyzed lobbying experiments on the effect of similarities of firms' interests on investment by setting three different sets of parameters; (1) $\alpha=1$, (2) $\alpha=0.75$, and (3) $\alpha=0.5$. Similar to the literature, we observed that subjects over-invested and the variance was large, but they played close the Nash equilibrium in the third case. So, subjects invested nothing when their interests were perfectly aligned. Furthermore, our regression outcomes rejected the hypothesis that the subjects behaved in the same way in any pairs of the above mentioned three cases. Therefore, the subjects behaved differently under a different structure of interests. Further, our model can be interpreted as two firms with cross holding shares engage in lobbying activities. A practical example is lobbying activities of two firms against the industry regulation such as the oil companies lobbying against environmental regulations. Further, our regression outcomes demonstrated that we could not reject the hypothesis that subjects' behaviors were the same between simultaneous and sequential contests, which supported our theoretical results, but was rarely observed in the literature. Our model is also applicable to the case where an incumbent is against entry promotion while an entrant is in favor of it as happened in the Japanese mobile phone industry.Although our model is very simple, we can extend it in several ways. Firstly, we can incorporate more complicated contest success functions such asSkaperdas, (n.d.) used. Secondly, we can analyze convex cost functions. Thirdly, we can introduce more than two firms. While it is obvious to extend the simultaneous model to more than two firms, calculating the subgame perfect Nash equilibrium for the sequential game with general $n>2$ firms is cumbersome although it is possible. Fourthly, we can easily introduce general shareholders into the model which allows $0<\alpha_{i i}+\alpha_{i j}<1,0<\alpha_{i i}<1$, and $0<\alpha_{i j}<1(i \neq j)$. 


\section{References}

i. $\quad$ Baba, Y., 2014. The effect of the exchange rate on investment in the Tullock contests. Mimeo : s.n.

ii. Baba, Y., n.d. A Note on a Comparison of Simultaneous and Sequential Colonel Blotto Games. Aoyama Keizai Ronshu, Volume 61, pp. 87-106.

iii. Binmore, K. \& Shaked, A., n.d. Experimental Economics: Where Next?. Journal of Economic Behavior \& Organization, , 73(1), pp. 87-100.

iv. $\quad$ Chowdhury, S., Sheremeta, R. \& Tyrocy, T., 2014. Overbidding and Overspending Rent-Seeking Experiments: Cost Structure and Prize Allocation Rules, Working Paper, s.l.: s.n.

v. Clark, D. \& Riis., C., n.d. Contest Success Functions: An Extension. Economic Theory, 11(1), pp. 201-204.

vi. $\quad$ Gurtler, O., 2005. Rent Seeking in Sequential Group Contests, Mimeo: s.n.

vii. Holt, C. \& Laury, S., n.d. Risk Aversion and Incentive Effects. American Economic Review , 92(5), pp. 1644-1655.

viii. Irfanoglu, Z., Mago, S. \& Sheremeta, R., 2010. Sequential versus Simultaneous Election Contests: An Experimental Study, Mimeo: s.n.

ix. Megidish, R. \& Sela, A., n.d. Sequential Contests with Synergy and Budget Constraints. Social Choice and welfare , 42(1), pp. 215-243.

x. $\quad$ Morgan, J., n.d. Sequential Contest. Public Choice, 116(1), pp. 146-161.

xi. $\quad$ Nitzan, S., n.d. Modeling Rent Seeking Contests. Europea Journal of Political Economy, 10(1), pp. 41-60.

xii. Price, C. \& Sheremeta, R., n.d. Endowment Effects in Contests. Economics letters, 111(3), pp. 217-219.

xiii. Sela, A., n.d. Sequential Two-Prize Contests. Economic Theory , 51(3), pp. 383-395.

xiv. Sheremeta, R., Dechenaux, E. \& Knovenock, K., n.d. A Survey of Experimental Research on Contests, All-Pay Auctions and Tournaments. Experimental Economics, Volume 18, pp. 609-669.

xv. Sheremeta, R., n.d. Contest Design: An Experimental Investigation. Economic Inquiry, 49(2), pp. 573-590.

xvi. Sheremeta, R., n.d. Overbidding and Heterogeneous Behavior in Contest Experiments. Journal of Economic Surveys , 27(3), pp. 491-514.

xvii. $\quad$ Skaperdas, S., n.d. Contest Success Functions. Economic Theory, 7(2), pp. 283-290.

xviii. Tullock, G., 1980. Efficient Rent-seeking. In: e. a. J.M. Buchanan, ed. Toward a Theory of the Rent-seeking Society. College Station: Texas A\&M Press. 